OPEN ACCESS

Edited by:

Haifeng Qiu,

Zhengzhou University, China

Reviewed by:

Raffaella Ergasti,

Università Cattolica

del Sacro Cuore, Italy

Elena Teodorico,

Agostino Gemell

University Polyclinic, Italy

*Correspondence:

Amanda R. Schwartz

amanda.rae.schwartz@gmail.com

Specialty section:

This article was submitted to

Gynecological Oncology,

a section of the journal

Frontiers in Oncology

Received: 19 February 2021

Accepted: 24 May 2021

Published: 11 June 2021

Citation:

Schwartz AR, Bartlett DB,

Johnson JL, Broadwater G,

Channell M, Nolte KC, Wilkes PA,

Huffman KM and Secord AA (2021)

A Pilot Study of Home-Based

Exercise and Personalized Nutrition

Counseling Intervention in

Endometrial Cancer Survivors.

Front. Oncol. 11:669961.

doi: 10.3389/fonc.2021.669961

\section{A Pilot Study of Home-Based Exercise and Personalized Nutrition Counseling Intervention in Endometrial Cancer Survivors}

\author{
Amanda R. Schwartz ${ }^{1 *}$, David B. Bartlett ${ }^{2}$, Johanna L. Johnson ${ }^{3}$, Gloria Broadwater ${ }^{4}$, \\ Meghan Channell ${ }^{5}$, Kimberly C. Nolte ${ }^{6}$, Patricia A. Wilkes ${ }^{7}$, Kim M. Huffman ${ }^{3,8}$ \\ and Angeles Alvarez Secord ${ }^{6}$ \\ 1 Department of Obstetrics and Gynecology, Duke University Hospital, Durham, NC, United States, ${ }^{2}$ Department of \\ Medicine, Division of Medical Oncology, Duke University Hospital, Durham, NC, United States, ${ }^{3}$ Duke Molecular Physiology \\ Institute, Duke Center for Living, Duke University, Durham, NC, United States, ${ }^{4}$ Department of Biostatistics and \\ Bioinformatics, Duke Cancer Institute, Duke University Medical Center, Durham, NC, United States, ${ }^{5}$ Department of Clinical \\ Research, Duke Cancer Institute, Duke University Medical Center, Durham, NC, United States, ${ }^{6}$ Division of Gynecologic \\ Oncology, Department of Obstetrics and Gynecology, Duke Cancer Institute, Duke University Health System, Durham, \\ NC, United States, ${ }^{7}$ Department of Nutrition Services, Duke University Hospital, Durham, NC, United States, ${ }^{8}$ Department of \\ Medicine, Division of Rheumatology, Duke University Hospital, Durham, NC, United States
}

Introduction: To assess the feasibility of a home-based aerobic exercise and nutrition counseling intervention and effect on cardiorespiratory fitness, cardiovascular disease risk profile, and immune response in obese endometrial cancer survivors.

Methods: A longitudinal pilot study assessed a 12-week home-based aerobic exercise and nutrition counseling intervention in obese endometrial cancer survivors. The primary outcome was feasibility defined as $80 \%$ adherence to weekly walking sessions calculated among individuals that completed the intervention. Secondary outcomes comprised preand post-intervention differences in cardiorespiratory fitness, cardiovascular risk factors, and T-cell function. Descriptive statistics summarized data. Wilcoxon sign tests identified differences between and pre and post-intervention variables.

Results: Nineteen women with stage 1 endometrial cancer consented; 9 withdrew and one was a screen failure. Median adherence to weekly walking sessions was $83.3 \%$. Body composition was significantly altered with a reduction in median fat mass from $52.5 \mathrm{~kg}$ to $46.9 \mathrm{~kg}$ ( $p=0.04$ ), and BMl from $37.5 \mathrm{~kg} / \mathrm{m} 2$ to $36.2 \mathrm{~kg} / \mathrm{m} 2$ ( $p=0.004)$. There was no significant difference in cardiorespiratory fitness or cardiovascular parameters. The percentage of $\mathrm{CD}^{+}$and $\mathrm{CD} 8^{+} \mathrm{T}$-cells producing IFN $\gamma$ towards MAGE-A4 significantly increased from and $5.9 \%$ to $7.2 \%(p=0.043)$ and $13.9 \%$ to $14.8 \%(p=0.046)$, respectively. There were 3 related adverse events: hip pain, back sprain, and abdominal pain.

Discussion: Our home-based exercise and nutrition counseling program was feasible based on $80 \%$ adherence to walking sessions and favored altered body composition. However, the discontinuation rate was high and further research is needed to overcome 
barriers to implementation. Improvement in cardiovascular parameters will most likely require longer and more intensive programs.

Keywords: endometrial cancer, obesity, cardiovascular disease, exercise intervention study, nutrition intervention program

\section{INTRODUCTION}

Endometrial cancer is the sixth most common malignancy in women with over 380,000 new cases globally in 2018 (1). The majority of women are diagnosed with localized disease, and in the United States alone there are approximately 727,700 endometrial cancer survivors (2).

Endometrial cancer is an obesity-driven malignancy, with the alarming rates of obesity contributing to increases in incidence and mortality.

Obesity negatively impacts prognosis for endometrial cancer patients with a meta-analysis of women with endometrial cancer showing that a $10 \%$ increase in BMI increased odds of all-cause mortality by $9.2 \%$ (3). Calle et al. reported that morbidly obese $(\mathrm{BMI}>40)$ endometrial cancer survivors had a 6.25 times increased risk of death compared to normal weight endometrial cancer survivors, with cardiovascular disease (CVD) being the leading cause of death (4). Felix and colleagues reported that women with endometrial cancer were 8.8 times more likely to die of CVD compared to women in the general population (5).

Therefore, we conducted a pilot study evaluating a 12-week home-based physical activity and nutrition counseling intervention to assess feasibility, safety, and effect on the cardiorespiratory fitness, CVD risk profile, and immune response endometrial cancer survivors.

\section{MATERIALS AND METHODS}

\section{Hypothesis and Study Objectives}

We hypothesized that a 12-week home-based exercise and personalized nutrition counseling intervention will be both feasible and safe among endometrial cancer survivors. Our primary objective was to assess the feasibility of the intervention, defined as $80 \%$ adherence to prescribed weekly walking sessions among individuals that completed the intervention. Our secondary objectives were to evaluate the safety of the program as well as its effects on the cardiorespiratory fitness, cardiovascular risk factors and immune response.

\section{Patient Selection}

Women with early stage localized endometrial cancer were recruited from the Duke Gynecologic Oncology clinic from May 2017 through July 2018. The inclusion criteria were as follows: age greater than 18 years; localized endometrial cancer (stage I and II); at least two months since hysterectomy and planned intervention date; Karnofsky performance status $\geq 70 \%$; BMI 30.0 - 49.9; body weight < 300 pounds; no plan for adjuvant endometrial therapy; ability to exercise safely on a treadmill; reliable transportation; ability to provide informed consent; ability to speak and understand English; and ownership of a personal mobile device compatible with the study activity monitor. Individuals scheduled to undergo adjuvant endometrial therapy were excluded secondary to concern that further therapies may limit their ability to participate in scheduled exercise. Patients were excluded if they were already participating in more than 60 minutes of moderate intensity or 30 minutes of vigorous intensity exercise per week, or weight reduction dieting. This exercise criteria, which is well below American Heart Association recommendations for adult physical activity, was selected in order to identify patients most likely to benefit from the intervention. Patients with any absolute contraindications to exercise testing based on American Thoracic Society criteria were excluded.

\section{Study Design}

The pilot study consisted of 12 weeks of home-based exercise and nutrition intervention with pre and post-intervention testing. IRB approval was obtained (Pro00074542).

Eligible patients underwent pre-intervention cardiorespiratory fitness and laboratory testing and body composition measurements including BOD POD assessment of body fat percentage. BOD POD uses air displacement plethysmography to provide a precise scale and volume measurement of body composition.

As an exploratory analysis, pre and post-intervention T-cell function was assessed. Tumor-associated antigen (TAA) specific $\mathrm{T}$-cells were generated by co-culturing peripheral blood mononuclear cells (PBMCs) with peptide pulsed dendritic cells generated from the THP-1 (ATCC, VA, USA) monocytic cell line similar to previous methods (6).

Exercise recommendations included 10,000 steps per day and five weekly walking sessions for 25-30 minutes at a moderate intensity, defined as being able to carry on a brief conversation, but not able to sing or a $12-14$ on the Borg Rating of Perceived Exertion scale. Daily steps were recorded by the FitBit (San Francisco, CA) activity monitor and walking sessions recorded in the exercise diary. Nutrition counseling was provided by a trained dietician (PAW) with recommended individualized daily caloric intake based on adjusted body weight to achieve weight loss. Participants were contacted every few weeks to provide support, assess progress and identify safety concerns. After the 12-weeks, post-intervention testing and a qualitative assessment were performed.

Any adverse events that occurred during the study duration were reviewed and signed off by the principal investigator and reported to the IRB in accordance with current policies.

\section{Data Analysis and Statistics}

The primary outcome of this longitudinal pilot study was feasibility, defined by $80 \%$ median adherence to weekly walking sessions among women completing the intervention. Adherence to weekly walking sessions was defined as walking 
25 - 30 minutes at a moderate intensity as reported in the participant's exercise diary. Based on previous exercise trial experience a dropout rate of $25 \%$ was anticipated with a plan to enroll 15 subjects to achieve program completion for 10 women. Safety of the study was assessed by the type and prevalence of adverse events during the course of the pilot study.

Descriptive statistics were used to summarize the data. Wilcoxon sign tests were used to test for differences between pre and post-intervention variables. Statistical analysis was conducted using SAS v. 9.4 software.

\section{RESULTS}

\section{Patient Selection and Demographics}

19 women meeting inclusion criteria were consented; one was a screen failure and 9 withdrew (Figure 1). Eight of the 9 women that withdrew from the study, discontinued during the preintervention period. Only one patient withdrew after initiation of the exercise and nutrition counseling intervention. Reasons for withdrawal included inability to commit to the study due to time requirements $(n=1)$, claustrophobia during BOD POD assessment $(\mathrm{n}=1)$, and unknown $(\mathrm{n}=7)$.

Nine patients enrolled and completed the study (Table 1).

\section{Feasibility and Safety}

The median adherence to prescribed weekly walking sessions for women completing the intervention was $83.3 \%(45.8 \%-91.7 \%)$ and the mean adherence was $85.7 \%(41.6 \%$ - 100\%) (Table 2). There were three study-related adverse events: abdominal pain $(\mathrm{n}=1)$; back sprain $(\mathrm{n}=1)$ and unilateral hip pain $(\mathrm{n}=1)$. The abdominal pain and back sprain resolved on study. The participant with unilateral hip pain was lost to follow up.

\section{Cardiorespiratory Fitness, Cardiovascular Disease Risk Factors}

There were no significant differences from baseline to postintervention markers of cardiorespiratory fitness or CVD. A significant decrease in total body mass was observed from visit 2 median body mass of $99.7 \mathrm{~kg}$ to visit 6 median body mass of

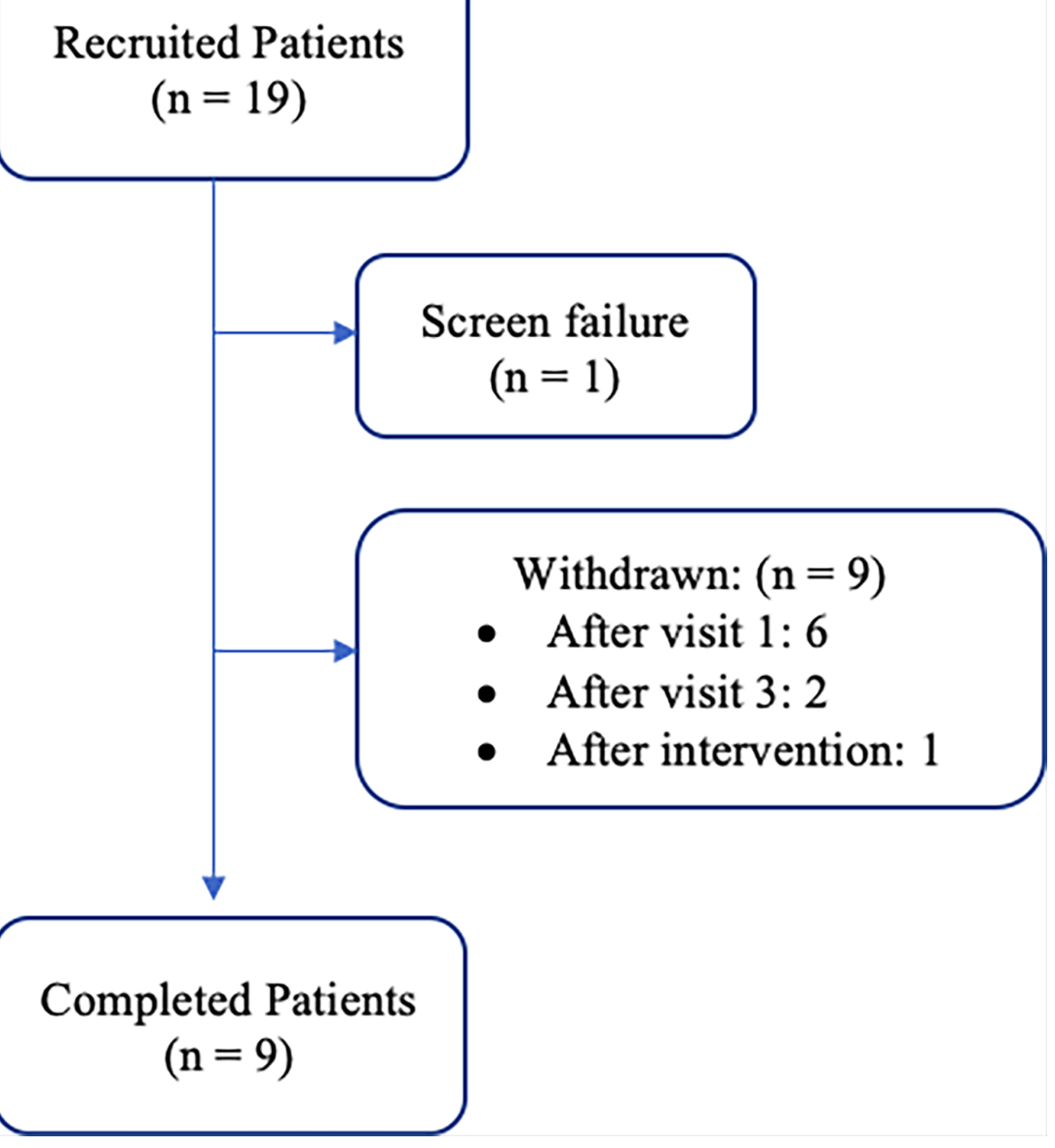

FIGURE 1 | Patient cohort flow diagram: recruitment and retention of participants throughout the duration of the study period. 
TABLE 1 | Patient Demographics.

\begin{tabular}{lc}
\hline Patient Characteristic & Patient cohort (n = 9) \\
\hline Age in years, median (Range) & $64.8(57.8-71.1)$ \\
BMI in kg/m², median (IQR) & $37.5(35.2-39.5)$ \\
Race: N (\%) & $6(66.7)$ \\
Caucasian: & $3(33.3)$ \\
African American & $0(0.0)$ \\
Other: & \\
Ethnicity: N (\%) & $9(100.0)$ \\
Not Hispanic or Latino & $0(0.0)$ \\
Hispanic or Latino & \\
Histology: N (\%) & $9(100.0)$ \\
Endometrioid & \\
Grade: N (\%) & $8(88.9)$ \\
Grade 1: & $1(11.1)$ \\
Grade 2: & \\
FIGO Stage 2009: N (\%) & $9(100.0)$ \\
Stage IA & \\
Performance Status: N (\%) & $4(44.4)$ \\
Karnofsky 90 & $5(55.6)$ \\
Karnofsky 100 &
\end{tabular}

${ }^{1} \mathrm{QQR}$, interquartile range.

$93.8 \mathrm{~kg}(\mathrm{p}=0.004$; Table 3). Similarly, there was a significant decrease in total fat mass $(\mathrm{p}=0.04)$ and BMI $(\mathrm{p}=0.004)$.

\section{Immune Function}

Of the nine participants, blood samples for immune assessment were available for five women, and samples were not available for four [processing issue $(n=2)$; limited venous access $(n=2)$ ]. Following a six-hour stimulation, the percentage of $\mathrm{CD}^{+}$and $\mathrm{CD}^{+}{ }^{+}$-cells producing IFN $\gamma$ towards MAGE-A4 significantly increased from and $5.9 \%$ to $7.2 \%(\mathrm{p}=0.043)$ and $13.9 \%$ to $14.8 \%$ $(\mathrm{p}=0.043)$, respectively (Table 3$)$.

\section{Qualitative Assessment}

All nine women completing the study reported a positive experience on the telephone survey. Emerging themes in qualitative assessment of the study included increases in self-confidence, motivation, perception of energy levels and exercise tolerance (Table 4).

\section{DISCUSSION}

Our findings demonstrated that a home-based exercise and nutrition counseling program is feasible based on $80 \%$ adherence to walking sessions and favored altered body composition in those initiating the study exercise and nutrition intervention. The walking sessions were safe and there were no serious or life-threatening events. There was a high rate of dropout during the study pre-intervention phase of the study which included the baseline cardiorespiratory testing and BODPOD measurements. Given this high rate of discontinuation prior to the exercise and nutrition intervention, and lack of information regarding reason for withdrawal, further research is needed to overcome barriers to implementation.

No serious or life-threatening adverse events occurred during this study. The musculoskeletal injuries reported were likely secondary to increased activity and were similar to adverse events reported in previous weight-loss interventions (7-9). In addition, our findings revealed a significant decrease in total body mass, fat mass, and BMI.

There were no significant improvements in markers of cardiorespiratory fitness or other CVD risk factors observed. The presence of baseline EKG abnormalities in seven of nine patients was alarming and further highlights the need for intervention to improve the cardiovascular health of these women.

Our novel exploratory analyses of T-cell function show a significant improvement in IFN $\gamma$ production from $\mathrm{CD}^{4+}$ and $\mathrm{CD}^{+} \mathrm{T}$-cells towards the tumor associated antigen MAGE-A4, and a non-significant trend for MAGE-A3 suggesting that T-cells post-intervention are more capable of recognizing tumor antigens. In these women there was a significant increase in relative $\mathrm{VO}_{2 \text { peak }}(\mathrm{p}=0.043)$ suggesting a relationship with cardiorespiratory fitness and immune function. In healthy individuals, a single bout of exercise generated an enhanced $\mathrm{T}$ cell response to tumor antigens, suggesting a beneficial role for exercise and tumor control by T-cells (6). Whether improved Tcell response will result in reduced risk for endometrial cancer recurrence remains unclear. Though the mechanisms remain unknown, our findings suggest physical activity and diet may enhance cytotoxic T-cell responses to cancer antigens. A previous investigation of endometrial morphology and molecular pathways following bariatric surgery-induced weight loss demonstrated reduction in biomarkers of insulin resistance (hemoglobin A1C, HOMA-IR) and inflammation (hsCRP, IL-6) demonstrating potential mechanisms by which weight loss may impact endometrial cancer risk (10). Another investigation of biomarkers in obese women following bariatric surgery similarly

TABLE 2 | Activity and Nutrition Adherence.

Variable

Adherence to weekly walking sessions (5 of 7 days walked)

Days with a walking session (goal of $72 \%$ )

Mean steps per day

Total steps

Mean daily calories burned

Mean daily calories consumed

Mean adherence to prescribed walking sessions (60 sessions)
Median (IQR)

$83.3 \%(45.8 \%-91.7 \%)$

$78.6 \%(56.0 \%-90.5 \%)$

$9036(8125-9806)$

$759044(607949-804371)$

$2000(1700-2000)$

$2700(1800-3700)$

Mean (range)

$85.7 \%(41.6 \%-100 \%)$

${ }^{1} / Q R$, interquartile range. 
TABLE 3 | Pre and Post Intervention Markers of Cardiorespiratory Fitness, Cardiovascular Disease and Body Composition.

\begin{tabular}{|c|c|c|c|c|}
\hline Variable, median (IQR) ${ }^{1}$ & Pre-intervention & Post-intervention & Difference & $P$ value \\
\hline \multicolumn{5}{|l|}{ Cardiorespiratory Fitness Markers } \\
\hline Peak $\mathrm{aVO}_{2}^{2}$, in $\mathrm{L} / \mathrm{min}$ & $\begin{array}{c}1.5 \\
(1.4-1.7)\end{array}$ & $\begin{array}{c}1.6 \\
(1.4-1.7)\end{array}$ & $\begin{array}{c}0.0 \\
(-0.1-0.0)\end{array}$ & 0.73 \\
\hline Peak $\mathrm{rVO}_{2}{ }^{3}$, in $\mathrm{mL} / \mathrm{kg} / \mathrm{min}$ & $\begin{array}{c}16.3 \\
(14.6-17.8)\end{array}$ & $\begin{array}{c}16.7 \\
(15.7-19.8)\end{array}$ & $\begin{array}{c}-0.9 \\
(-2.5-0.1)\end{array}$ & 0.45 \\
\hline Peak respiratory exchange ratio & $\begin{array}{c}1.1 \\
(1.1-1.2)\end{array}$ & $\begin{array}{c}1.1 \\
(1.0-1.2)\end{array}$ & $\begin{array}{c}0.0 \\
(0.0-0.1)\end{array}$ & 1.00 \\
\hline Respiratory peak exchange & $\begin{array}{c}18.0 \\
(17.0-19.0)\end{array}$ & $\begin{array}{c}19.0 \\
(17.0-19.0)\end{array}$ & $\begin{array}{c}0.0 \\
(-2.0-0.0)\end{array}$ & 0.13 \\
\hline Resting systolic BP, in $\mathrm{mm} \mathrm{Hg}$ & $\begin{array}{c}122 \\
(122-126)\end{array}$ & $\begin{array}{c}120 \\
(114-118)\end{array}$ & $\begin{array}{c}4.0 \\
(0.0-6.0)\end{array}$ & 0.29 \\
\hline Resting diastolic $\mathrm{BP}$, in $\mathrm{mm} \mathrm{Hg}$ & $\begin{array}{c}78 \\
(72-80)\end{array}$ & $\begin{array}{c}78 \\
(74-86)\end{array}$ & $\begin{array}{c}0.0 \\
(-4.0-2.0)\end{array}$ & 1.00 \\
\hline Time to exhaustion, in seconds & $\begin{array}{c}375 \\
(327-471)\end{array}$ & $\begin{array}{c}418 \\
(372-454)\end{array}$ & $\begin{array}{c}-43.0 \\
(-79.0--12.0)\end{array}$ & 0.07 \\
\hline \multicolumn{5}{|c|}{ Cardiovascular Disease Risk Factors } \\
\hline C-reactive protein, in mg/L & $\begin{array}{c}4.2 \\
(3.0-6.1)\end{array}$ & $\begin{array}{c}4.4 \\
(2.6-6.3)\end{array}$ & $\begin{array}{c}0.4 \\
(-0.2-1.1)\end{array}$ & 0.73 \\
\hline Cholesterol, in mg/dL & $\begin{array}{c}195 \\
(171-216)\end{array}$ & $\begin{array}{c}196 \\
(153-236)\end{array}$ & $\begin{array}{c}-1.0 \\
(-14.0-9.0)\end{array}$ & 1.00 \\
\hline $\mathrm{HDL}^{4}$, in $\mathrm{mg} / \mathrm{dL}$ & $\begin{array}{c}50 \\
(38-67)\end{array}$ & $\begin{array}{c}61 \\
(36-65)\end{array}$ & $\begin{array}{c}-2.0 \\
(-3.0-2.0)\end{array}$ & 0.73 \\
\hline $\mathrm{LDL}^{5}$, in $\mathrm{mg} / \mathrm{dL}$ & $\begin{array}{c}117 \\
(71-132)\end{array}$ & $\begin{array}{c}116 \\
(102-151)\end{array}$ & $\begin{array}{c}-4.0 \\
(-19.0-6.0)\end{array}$ & 1.00 \\
\hline $\mathrm{TG}^{6}$, in $\mathrm{mg} / \mathrm{dL}$ & $\begin{array}{c}112 \\
(90-124)\end{array}$ & $\begin{array}{c}106 \\
(68-114)\end{array}$ & $\begin{array}{c}13.0 \\
(5.0-25.0)\end{array}$ & 0.18 \\
\hline \multicolumn{5}{|c|}{ Body Measurements and Composition } \\
\hline Body Mass, in kg & $\begin{array}{c}99.7 \\
(97.3-104.2)\end{array}$ & $\begin{array}{c}93.8 \\
(91.8-99.4)\end{array}$ & $\begin{array}{c}4.0 \\
(3.5-5.5)\end{array}$ & 0.004 \\
\hline Body Mass Index, in $\mathrm{kg} / \mathrm{m}^{2}$ & $\begin{array}{c}37.5 \\
(35.9-41.2)\end{array}$ & $\begin{array}{c}36.2 \\
(34.1-39.0)\end{array}$ & $\begin{array}{c}2.3 \\
(1.4-2.9)\end{array}$ & 0.004 \\
\hline Fat mass, in $\mathrm{kg}$ & $\begin{array}{c}52.5 \\
(45.0-54.7)\end{array}$ & $\begin{array}{c}46.9 \\
(43.4-50.8)\end{array}$ & $\begin{array}{c}2.1 \\
(1.4-5.8)\end{array}$ & 0.04 \\
\hline Hip circumference, in cm & $\begin{array}{c}123.4 \\
(111.6-127.3)\end{array}$ & $\begin{array}{c}122.8 \\
(113.3-127.3)\end{array}$ & $\begin{array}{c}2.5 \\
(1.1-3.3)\end{array}$ & 0.18 \\
\hline Lung volume, in liters & $\begin{array}{c}3.3 \\
(3.1-3.3)\end{array}$ & $\begin{array}{c}3.3 \\
(3.1-3.3)\end{array}$ & $\begin{array}{c}0.0 \\
(0.0-0.0)\end{array}$ & - \\
\hline Percentage body fat & $\begin{array}{c}51.6 \\
(50.6-54.0)\end{array}$ & $\begin{array}{c}51.1 \\
(48.3-55.0)\end{array}$ & $\begin{array}{c}0.0 \\
(-1.0-1.8)\end{array}$ & 1.00 \\
\hline Percentage lean mass & $\begin{array}{c}48.4 \\
(45.5-49.4)\end{array}$ & $\begin{array}{c}51.0 \\
(48.6-53.0)\end{array}$ & $\begin{array}{c}-0.9 \\
(-2.6-0.8)\end{array}$ & 0.73 \\
\hline Waist circumference, in cm & $\begin{array}{c}118.6 \\
(114.8-122.3)\end{array}$ & $\begin{array}{c}112.9 \\
(111.3-117.5)\end{array}$ & $\begin{array}{c}3.5 \\
(1.1-5.7)\end{array}$ & 0.18 \\
\hline \multicolumn{5}{|l|}{ Immune Function } \\
\hline CD4+ T-cells (\% of Lymphocytes) & $\begin{array}{c}60 \\
(57-62)\end{array}$ & $\begin{array}{c}61.5 \\
(57-62.5)\end{array}$ & $\begin{array}{c}1.0 \\
(-0.5-1.3)\end{array}$ & 0.257 \\
\hline \multicolumn{5}{|l|}{$\mathrm{CD} 4+/ \mathrm{IFN} \gamma+(\%)$} \\
\hline MAGE-A3 & $\begin{array}{c}6.9 \\
(4.9-7.4)\end{array}$ & $\begin{array}{c}7.2 \\
(5.8-9.1)\end{array}$ & $\begin{array}{c}1.0 \\
(0.2-2.0)\end{array}$ & 0.080 \\
\hline MAGE-A4 & $\begin{array}{c}6.0 \\
(4.5-7.2)\end{array}$ & $\begin{array}{c}7.2 \\
(5.3-9.2)\end{array}$ & $\begin{array}{c}0.8 \\
(0.9-2.2)\end{array}$ & 0.043 \\
\hline CD8+ T-cells (\% of Lymphocytes) & $\begin{array}{c}34.9 \\
(32.5-36.7)\end{array}$ & $\begin{array}{c}36.3 \\
(32.3-37)\end{array}$ & $\begin{array}{c}0.3 \\
(-1.0-1.6)\end{array}$ & 0.500 \\
\hline \multicolumn{5}{|l|}{$\mathrm{CD} 8+/ \mathrm{IFN} \gamma+(\%)$} \\
\hline MAGE-A3 & $\begin{array}{c}15.2 \\
(13.9-15.8)\end{array}$ & $\begin{array}{c}15.2 \\
(14.9-17.7)\end{array}$ & $\begin{array}{c}1.3 \\
(0.2-2.1)\end{array}$ & 0.080 \\
\hline MAGE-A4 & $\begin{array}{c}13.4 \\
(13.1-15.1)\end{array}$ & $\begin{array}{c}15.3 \\
(13.6-15.8)\end{array}$ & $\begin{array}{c}0.9 \\
(0.3-1.5)\end{array}$ & 0.043 \\
\hline
\end{tabular}

${ }^{1} / Q R$, interquartile range.

ªVO2, absolute peak oxygen consumption.

${ }^{3} \mathrm{rVO} 2$, relative peak oxygen consumption.

${ }^{4} \mathrm{HDL}$, high density lipoprotein.

${ }^{5} L D L$, low density lipoprotein.

${ }^{6} \mathrm{TG}$, triglyceride.

In bold: Statistically significant $(p<0.05)$. 
TABLE 4 | Free responses to qualitative prompts and corresponding themes.

Emerging theme

Increased self-confidence

Increased energy levels and exercise tolerance

Increased motivation and desire to continue beyond the 12-week intervention

Desire for more individualized nutrition counseling

\section{Patient quotes}

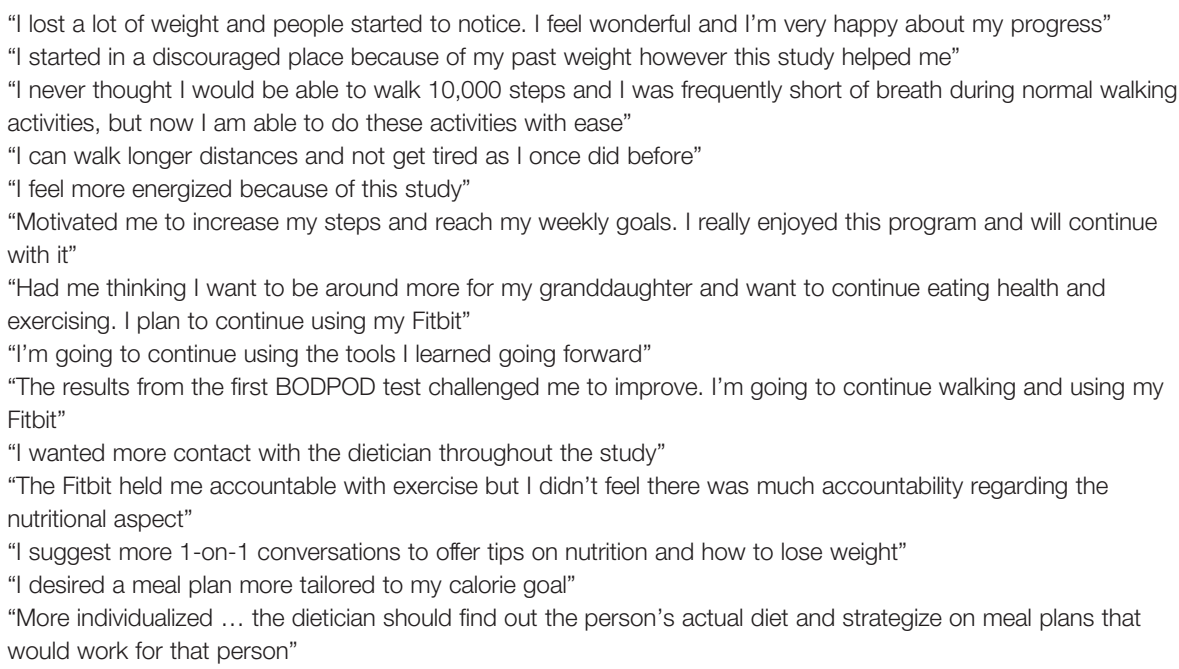

demonstrated reduction in inflammatory markers, including CRP, IL-1Ra and IL-6, following weight loss (11). The reduction in inflammatory markers following bariatric surgery suggest that weight loss contributes to a favorable immune environment that may restore the endometrium to a lower risk state. Our findings of an enhanced cytotoxic T-cell response following an exercise and nutrition counseling intervention further suggest a possible role of exercise and/or nutrition on immunologic response. Further investigation is needed to provide insight in potential regulatory mechanisms of exercise, nutrition, and/or weight loss on immune function.

Previous weight-loss interventions in other patient populations at increased risk of CVD have shown improvements in markers of cardiovascular fitness and CVD risk factors $(12,13)$. While improvement in body mass was seen in our pilot cohort, we believe that the lack of favorable changes on markers of cardiorespiratory fitness and lipid profile was secondary to the small sample size and short-term intervention.

Among endometrial cancer survivors, there have been limited high-quality exercise and nutrition counseling interventions. The SUCCEED trial, a six-month nutrition and exercise intervention among 70 obese endometrial cancer survivors, demonstrated an increase in physical activity and weight loss (7). Basen-Engquist and colleagues reported a home-based exercise intervention in endometrial cancer survivors which showed increased physical activity, improved predicted $\mathrm{VO}_{2 \mathrm{MAX}}$, and improved systolic blood pressure among the obese cohort (14). While these studies have shown promising results, a recent Cochrane analysis of interventions for weight loss in endometrial cancer survivors found no improvement in cancer-specific survival, overall survival, cardiovascular event frequency, or significant weight loss at six or twelve months (15).

The qualitative survey at the conclusion of the study indicated that the intervention was well received with all nine women reporting their experience to be beneficial and four specifically noting plans to continue to apply the lifestyle changes beyond the intervention period. Previous investigations of weight-loss interventions in endometrial cancer survivors have likewise shown improvements in self-efficacy and emotional well-being which correlate with weight loss $(8,12,16,17)$. The qualitative assessment was performed at the conclusion of the study and therefore qualitative data was limited to only those individuals that completed the intervention. Therefore, responses are more likely positive than from those who did not complete the intervention.

Key limitations of the study included small sample size and participant dropout. Improvements in cardiorespiratory fitness and markers of CVD will most likely require longer and more intensive intervention. Although feasibility criteria was met among individuals that initiated the exercise and nutrition intervention study phase, the generalizability of this pilot investigation is significantly limited by the small sample size. The $50 \%$ dropout rate is higher than in similar interventions aimed at weight loss in endometrial cancer survivors (19-22\%) and raises concern for withdrawal bias $(8,9)$. This exceeded our estimated dropout rate of $25 \%$ and ultimately resulted in a lower number of pilot study participants than originally anticipated. Patients were screened only by initial interest with many women choosing not to enroll after the study requirements were described in further detail and other women enrolling in the study but later being unable or unwilling to complete the study tasks. Given that the majority of the women that withdrew from the study did so prior to initiation of the exercise and nutrition counseling intervention, more thorough counseling of the pre-intervention testing requirements may contribute to lower rates of discontinuation in future trials. The more intensive requirement for cardiopulmonary exercise testing as well as the pre and post-intervention testing requiring additional transportation may have contributed to the higher dropout 
rate. Despite a high drop-out rate, the results of the qualitative assessment indicate that the intervention was well-received among the women that completed the study. Unfortunately, we are unable to identify the patients that are more likely to successfully complete the intervention at this point in time. Further measures to mitigate patient discontinuation, such as more detailed discussion of study participation at time of enrollment, centralization of study visits to a single site or closer follow-up throughout the duration of the study would need to be considered prior to application of this pilot intervention on a broader scale.

In conclusion, our pilot study represents a feasible and safe method of home-base physical activity and nutrition counseling intervention for endometrial cancer survivors which led to significant improvements in weight and BMI. However, longer and more intensive studies will be needed to determine if exercise and nutrition weight loss interventions will reduce the risk of CVD and mortality in endometrial cancer survivors. Our results will inform future study designs and support funding to conduct further studies on cardiovascular biomarkers and cardiovascular fitness in endometrial cancer survivors.

\section{DATA AVAILABILITY STATEMENT}

The raw data supporting the conclusions of this article will be made available by the authors, without undue reservation.

\section{REFERENCES}

1. Bray F, Ferlay J, Soerjomataram I, Siegel RL, Rotte LA, Jemal A. Global Cancer Statistics 2018: GLOBOCAN Estimates of Incidence and Mortality Worldwide for 36 Cancers in 185 Countries. CA: A Cancer J Clin (2018) 68 (6):394-424. doi: 10.3322/caac.21492

2. National Cancer Institute. Surveilance, Epidemiology and End Results Program: Cancer Stat Facts Uterine Cancer.

3. Secord AA, Hasselblad V, Von Gruenigen VE, Gehrig PA, Modesitt SC, BaeJump V, et al. Body Mass Index and Mortality in Endometrial Cancer: A Systematic Review and Meta-Analysis. Gynecologic Oncol (2016) 140(1):18490. doi: 10.1016/j.ygyno.2015.10.020

4. Calle EE, Rodriguez C, Walker-Thurmond K, Thun MJ. Overweight, Obesity, and Mortality From Cancer in a Prospectively Studied Cohort of U.S. Adults. New Engl J Med (2003) 348(17):1625-38. doi: 10.1056/NEJMoa021423

5. Felix AS, Bower JK, Pfeiffer RM, Raman SV, Cohn DE, Sherman ME. High Cardiovascular Disease Mortality After Endometrial Cancer Diagnosis: Results From the Surveillance, Epidemiology, and End Results (SEER) Database. Int J Cancer (2017) 140(3):555-64. doi: 10.1002/ijc.30470

6. LaVoy EC, Bollard CM, Hanley PJ, Blaney JW, O'Connor DP, Bosch JA, et al. A Single Bout of Dynamic Exercise Enhances the Expansion of MAGE-A4 and PRAME-Specific Cytotoxic T-Cells From Healthy Adults. Exerc Immunol Rev (2015) 21:144-53.

7. von Gruenigen V, Frasure H, Kavanagh MB, Janata J, Waggoner S, Rose P, et al. Survivors of Uterine Cancer Empowered by Exercise and Healthy Diet (SUCCEED): A Randomized Controlled Trial. Gynecologic Oncol (2012) 125 (3):699-704. doi: 10.1016/j.ygyno.2012.03.042

8. McCarroll ML, Armbruster S, Frasure HE, Gothard MD, Gil KM, Kavanagh MB, et al. Self-Efficacy, Quality of Life, and Weight Loss in Overweight/Obese Endometrial Cancer Survivors (SUCCEED): A Randomized Controlled Trial. Gynecologic Oncol (2014) 132(2):397-402. doi: 10.1016/j.ygyno.2013.12.023

\section{ETHICS STATEMENT}

The studies involving human participants were reviewed and approved by Duke Institutional Review Board. The patients/ participants provided their written informed consent to participate in this study.

\section{AUTHOR CONTRIBUTIONS}

AAS and $\mathrm{KH}$ played an active role in the design of the pilot study. The IRB was drafted by AAS. AAS, KH, and ARS participated in the obtaining of funding for the study. AAS, JJ, KN and MC participated in patient recruitment. PW created a personalized nutrition plan for each patient and completed individualized nutrition counseling. JJ and MC were integral to patient recruitment, calling patients throughout the study period and recording patient data. Exploratory analysis of T-cell function was performed by DB. Statistical analysis was performed by GB and DB. The research manuscript was drafted by ARS and AAS and edited by all listed authors. All authors contributed to the article and approved the submitted version.

\section{FUNDING}

Charles B Hammond Research Fund (awarded 12/2017), Duke University School of Medicine, Durham, NC.

9. Haggerty AF, Hagemann A, Barnett M, Thornquist M, Neuhouser ML Horowitz N, et al. A Randomized, Controlled, Multicenter Study of Technology-Based Weight Loss Interventions Among Endometrial Cancer Survivors. Obes (Silver Spring Md) (2017) 25(Suppl 2):S102-s8. doi: 10.1002/ oby. 22021

10. MacKintosh ML, Derbyshire AE, McVey RJ, Bolton J, Nickkho-Amiry M, Higgins CL, et al. The Impact of Obesity and Baritric Surgery on Circulating and Tissue Biomarkers of Endometrial Cancer Risk. Int J Cancer (2019) 144 (3):641-60. doi: 10.1002/ijc.31913

11. Linkov F, Goughnour SL, Ma T, Xu Z, Edwards RP, Lokshin AE, et al. Changes in Inflammatory Endometrial Cancer Risk Biomarkers in Individuals Undergoing Surgical Weight Loss. Gynecologic Oncol (2017) 147:133-8. doi: 10.1016/j.ygyno.2017.07.144

12. van Tol BA, Huijsmans RJ, Kroon DW, Schothorst M, Kwakkel G. Effects of Exercise Training on Cardiac Performance, Exercise Capacity and Quality of Life in Patients With Heart Failure: A Meta-Analysis. Eur J Heart Failure (2006) 8(8):841-50. doi: 10.1016/j.ejheart.2006.02.013

13. Slentz CA, Duscha BD, Johnson JL, Ketchum K, Aiken LB, Samsa GP, et al. Effects of the Amount of Exercise on Body Weight, Body Composition, and Measures of Central Obesity: STRRIDE-A Randomized Controlled Study. Arch Internal Med (2004) 164(1):31-9. doi: 10.1001/archinte.164.1.31

14. Basen-Engquist K, Carmack C, Brown J, Jhingran A, Baum G, Song J, et al. Response to an Exercise Intervention After Endometrial Cancer: Differences Between Obese and Non-Obese Survivors. Gynecologic Oncol (2014) 133 (1):48-55. doi: 10.1016/j.ygyno.2014.01.025

15. Kitson S, Ryan N, MacKintosh ML, Edmondson R, Duffy JM, Crosbie EJ. Interventions for Weight Reduction in Obesity to Improve Survival in Women With Endometrial Cancer. Cochrane Database Systematic Rev (2018) 2:Cd012513. doi: 10.1002/14651858.CD012513.pub2

16. von Gruenigen VE, Gibbons HE, Kavanagh MB, Janata JW, Lerner E, Courneya KS. A Randomized Trial of a Lifestyle Intervention in Obese Endometrial Cancer 
Survivors: Quality of Life Outcomes and Mediators of Behavior Change. Health Qual Life Outcomes (2009) 7:17. doi: 10.1186/1477-7525-7-17

17. Rossi A, Garber CE, Ortiz M, Shankar V, Goldberg GL, Nevadunsky NS. Feasibility of a Physical Activity Intervention for Obese, Socioculturally Diverse Endometrial Cancer Survivors. Gynecologic Oncol (2016) 142 (2):304-10. doi: 10.1016/j.ygyno.2016.05.034

Conflict of Interest: AAS reports grants from AbbVie, Amgen, Astex Pharmaceuticals Inc., Astra Zeneca, Clovis, Astellas Pharma Inc., Boehringer Ingelheim, Bristol Myers Squibb, Clovis, Eisai, Endocyte, Exelixis, Incyte, Merck, PharmaMar, Immutep Ltd, Roche/Genentech, Seattle Genetics, Inc, TapImmune, and Tesaro outside of submitted work. She reports honoraria from advisory boards with Alexion, Aravive, Astex Pharmaceuticals Inc., Astra Zeneca,
Cordgenics, Clovis, Janssen/Johnson \& Johnson, Merck, Mersana, Myriad, Oncoquest, Roche/Genentech, and Tesaro outside the submitted work.

The remaining authors declare that the research was conducted in the absence of any commercial or financial relationships that could be construed as a potential conflict of interest.

Copyright $\odot 2021$ Schwartz, Bartlett, Johnson, Broadwater, Channell, Nolte, Wilkes, Huffman and Secord. This is an open-access article distributed under the terms of the Creative Commons Attribution License (CC BY). The use, distribution or reproduction in other forums is permitted, provided the original author(s) and the copyright owner(s) are credited and that the original publication in this journal is cited, in accordance with accepted academic practice. No use, distribution or reproduction is permitted which does not comply with these terms. 